\title{
MODELING THE IMPACTS OF MARKET \\ ACTIVITY ON BID-ASK \\ SPREADS IN THE OPTION MARKET
}

\author{
Young-Hye Cho \\ Robert F. Engle \\ Working Paper 7331 \\ http://www.nber.org/papers/w7331
NATIONAL BUREAU OF ECONOMIC RESEARCH
1050 Massachusetts Avenue
Cambridge, MA 02138
September 1999

We thank Clive W. Granger, Allan Timmermann, Kenneth Kroner, Bruce Lehmann, Alex Kane, and Giampiero M. Gallo for discussions and suggestions. We are grateful to Halbert White for the data. This paper has also benefited from comments of seminar participants at ESSEC, France, 1999. We are solely responsible for any error. The views expressed herein are those of the authors and not necessarily those of the National Bureau of Economic Research.

(C) 1999 by Young-Hye Cho and Robert F. Engle. All rights reserved. Short sections of text, not to exceed two paragraphs, may be quoted without explicit permission provided that full credit, including $\odot$ notice, is given 
to the source.

Modeling the Impacts of Market Activity

on Bid-Ask Spreads in the Option Market

Young-Hye Cho and Robert F. Engle

NBER Working Paper No. 7331

September 1999

JEL No. G14

\section{ABSTRACT}

In this paper, we examine the impact of market activity on the percentage bid-ask spreads of S\&P 100 index options using transactions data. We propose a new market microstructure theory which we call derivative hedge theory, in which option market percentage spreads will be inversely related to the option market maker's ability to hedge his positions in the underlying market, as measured by the liquidity of the latter market. In a perfect hedge world, spreads arise from the illiquidity of the underlying market, rather than from inventory risk or informed trading in the option market itself.

We find option market volume is not a significant determinant of option market spreads. This finding leads us to question the use of volume as a measure of liquidity and supports the derivative hedge theory. Option market spreads are positively related to spreads in the underlying market, again supporting our theory. However, option market duration does affect option market spreads, with very slow and very fast option markets both leading to bigger spreads. The fast market result would be predicted by the asymmetric information theory. Inventory model predicts big spreads in slow markets. Neither result would be observed if the underlying securities market provided a perfect hedge. We interpret these mixed results as meaning that the option market maker is able to only imperfectly hedge his positions in the underlying securities market.

Our result of insignificant options volume casts doubt on the price discovery argument between stock and option market (Easley, O’Hara, and Srinivas (1998)). Asymmetric information costs in either market are naturally passed to the other market maker's hedging and therefore it is unimportant where the informed traders trade.

Young-Hye Cho

Department of Finance and Economiespartment of Economics, 0508

Graduate School of Management

Rutgers University

New Brunswick, NJ 08903

ycho@business.rutgers.edu
University of California -- San Diego

9500 Gilman Drive

La Jolla, CA 92093-0508

and NBER 
rengle@ucsd.edu 


\section{Introduction}

Widespread attention has been focused on the question of how bid-ask spreads are affected by the level of market activity. Inventory and asymmetric information models purport to explain the relationship between market activity and spreads. Although these models have been developed to explain the relation between spreads and stock market activity, they should be applicable to option market spreads and their market activity as well. However, bid-ask spreads in derivative markets, especially in option markets, may be determined not only by their own market but also by underlying market activity. In this case, option spreads should be examined in terms of activities in both markets.

This paper examines the impact of market activity on the percentage bid-ask spreads of S\&P 100 index options using transaction data. For this purpose, we propose a new market microstructure theory called "derivative hedge theory" in order to address the relation between options and underlying asset markets. If market makers in derivative markets can perfectly hedge their positions with an underlying security, then liquidity and spreads in derivative markets will be determined by liquidity in the underlying market. Therefore, in a perfect derivative-hedge world, spreads arise because of the illiquidity of an underlying market, rather than because of inventory risk or informed trading in the option market itself. Spreads in option markets increase when there is informed trading in the underlying market.

We model bid-ask percentage spreads in relation to market activities in order to investigate market microstucture theories to explain option market makers' quoting. For this purpose, we propose three models: a static model, a dynamic model, and a crossmarket model. The last includes cross-option market as well as underlying market 
effects. In the static model bid-ask percentage spreads in option markets are explained by the main characteristics of option contracts: moneyness, time to maturity and option prices and by underlying stock market activities such as hedge ratios and volatility. Duration and average volume per transaction, measures of trading intensity are added in the dynamic model. The cross-market model includes in addition, cross-option market activity measured by the inverse of cross-options transaction duration and underlying stock market activity measured by the average percentage spreads of the underlying stocks. In particular, variables that allow us to evaluate the three market microstructure theories are specified. Variables such as the average volume of options transactions, duration between transactions and the average percentage spreads of underlying securities enable us to distinguish the role of these models in option spreads.

Our results support the derivative hedge theory: option market spreads are not significantly affected by option market volume, but are positively related to spreads in the underlying market. With the availability of a perfect hedges, option market activities should not explain option spreads; however, the underlying market does not appear to offer a perfect hedge as both long and short durations in the option market lead to widening spreads.

Examining the implications of option market activities as well as options trading's relation to the underlying market provide one possible explanation of the price discovery argument. Easley, O'Hara and Srinivas (1998) show that option markets are a venue for informed trading and that the future courses of stock prices can be predicted from the volume and type of options traded. However, our finding of the insignificant explanatory power of option volume casts doubt on this price discovery argument. Asymmetric 
information costs in either market are immediately passed to the other market by the option market maker's hedging and therefore the location at which informed traders trade is not important.

This paper is organized as follows. In section II, we discuss the inventory and asymmetric information market microstructure theories. We also propose our derivative hedge theory. In section III, we describe the data and the statistics on transactions in option markets. In section IV, we present the static model to explain the spreads in option markets. Section $\mathrm{V}$ extends the static model to a dynamic one, incorporating the relation to option market activities. In section VI, the cross-market model for the relation between option spreads and cross-option market activities as well as underlying stock market activities are presented. In section VII, we discuss the empirical results in the framework of market microstructure theories with a critical view at the price discovery arguments. Section VIII concludes.

\section{Market Micro-Structure Theories of Derivative Markets}

When market microstructure theories seek to explain order arrival and quote revision, the central concept is liquidity. Liquidity is the price of immediacy. A market is liquid if traders can buy and sell many shares quickly and at a price close to the previously prevailing price with a low transaction cost. This is a function of traders and market markers' willingness to take the opposite side of a trade.

However, liquidity is difficult to measure as it is not easy to distinguish between normal price movements and price movements resulting from large orders. One of the 
most frequent proxies is the bid-ask spread because it represents the average cost of a round-trip transaction of a normally traded quantity.

Bid-ask spreads can be explained by the inventory and asymmetric information theories. According to the inventory theory, the bid-ask spread exists to compensate market makers for bearing the risk of holding undesired inventory. That is, when there is an order imbalance that moves the market maker away from his desired level of inventory, he adjusts the bid-ask spread to attract orders and re-optimize his inventory position. Therefore, the market maker increases the spread as the inventory imbalance accumulates (Amihud and Mendelson (1980), Ho and Stoll (1983), and Stoll (1989)). ${ }^{1}$

While the inventory model depends on the assumption of the market maker's risk aversion, in asymmetric information models, the market maker can be risk neutral. This model assumes the existence of traders with superior information. Given his informational disadvantage, the market maker must keep spreads wide enough to compensate for losses he experiences through trading with informed traders. Trading costs arise solely from the presence of informed traders, whose profits are made at the expense of the uninformed liquidity traders. ${ }^{2}$ That is, adverse selection imposes a cost

${ }^{1}$ According to the model presented by Stoll (1989), the bid-ask spread increases with the size of trades, with both risk aversion and volatility while it does not depend on the size of inventory. Several empirical studies attempt to explain bid-ask spreads in inventory models. Lee, Mucklow, and Ready (1993) show that the bid-ask spreads for NYSE stocks become wider in response to higher trading volume. Hasbrouck and Sofianos (1993) show that the trades in which NYSE specialists participate tend to have a bigger and more rapid effect on spreads than trades with no specialist participation. Madhavan and Smidt (1993) report that bid-ask quote revisions are positively related to order imbalances. George and Longstaff (1993) develop taxonomy of spreads for the S\&P100 index options in terms of inventory cost. They argue that the cross sectional differences in the S\&P100 index option bid-ask spread should be related to cost-related variables.

${ }^{2}$ In a one-period model, Copeland and Galai (1983) formalize the idea by considering the market maker's profit maximization problem with asymmetric information and find that nothing further is required to induce spreads. ${ }^{2}$ They predict that the spread increases with price level and volatility but decreases with market activity, depth, continuity, and the degree of competition. As 
that must be made up by a spread, even for a risk neutral, competitive market maker. (Copeland and Galai (1983), Glosten and Milgrom (1985), and Easley and O'Hara (1987)).

However, the bid-ask spread in derivative markets, and especially in option markets may be determined not only by derivative market activity but also by activity in the underlying market. Therefore we propose our derivative hedge theory which focuses on the relationship between liquidity in the underlying market and hedge risk in the derivative markets. The derivative market maker can access not only the liquidity of the derivative market but also, by hedging his position in the underlying security market, the liquidity of that deeper market. If the market maker in the derivative markets hedges all his positions, then he will no longer be subject to either inventory or asymmetric information risks in that market. In other words, if he trades with informed traders and hedges his position perfectly, he will not be hurt by such trades since the liquidity in the market will be a function of the liquidity in the underlying market, rather than of the activity of the derivative market. Thus, if there are informed traders in the underlying markets, then the spreads in those markets will be wide and the spreads in the derivative market will also be wide. Here, spreads in the derivative markets exist because market makers in those markets find it difficult to hedge their position because of an illiquid underlying market.

a result, higher volume measured by number of transactions is associated with lower spreads. Glosten and Milgrom (1985) and Easley and O'Hara (1987) develop dynamic models where transactions signal information. In the Glosten and Milgrom model, a buying order results in an increase in spread because the market maker increases his valuation of the asset; the opposite revision occurs with a selling order. Easley and O'Hara allow for different sized trades and assume that informed traders prefer larger size transactions. Adverse selection arises because a market maker interprets large orders as a signal of informed trading and adjusts the price and spread accordingly. 
Therefore, asymmetric information and derivative hedge theory give different interpretations for the derivative market activity measured by volume and for the price discovery argument between underlying security market and derivative market. Option markets have been regarded, according to Black (1974), as an ideal venue for informed trading because of low transaction costs, less stringent margin conditions, and the absence of the uptick rule for shorting. This leads to the role of information in price discovery between stock markets and option markets. According to the asymmetric information model if there are venues where informed traders gather, then the location of informed trading may have implications of price discovery between markets. Easley, O'Hara, and Srinivas (1998) investigate informational linkage between option markets and equity markets, examining the role of transaction volume in option markets. ${ }^{3}$ Given that information is incorporated into prices through the trading activity, if the option market is more attractive to informed traders, then options transactions would be informative for future stock prices. ${ }^{4}$ However, according to derivative hedge theory, the informational linkage between options and stock markets for price discovery become irrelevant, since the informed options trading activity may be revealed in imbalances in the hedge positions in the market marker's accounts on the underlying asset. Since it is the liquidity of the underlying market that determines whether the option market maker

3 The role of options in impounding information into security prices is not a new idea. See Manaster and Rendleman (1982), Bhattacharya (1987), Vijh (1990), Anthony (1988), Stoll and Whaley (1990), Stephen and Whaley (1990), Chan, Chung and Johnson (1993), Sheikh and Ronn (1994), Mayhew, Sarin and Shastri (1995), Fleming, Ostdiek, and Whaley (1996) for the empirical examinations of the relation between options and equity markets.

4 In their model, "positive news" option volumes (buying a call or selling a put) provides a positive signal for stock price movement to all market makers, who then increase their bid and ask prices while "negative news" options volumes (selling a call or buying a put) depresses quotes 
can perfectly hedge his position, there may be no causality from option volume to stock price movement. Furthermore, asymmetric information costs in either market are naturally passed to the other market by the market maker's hedging and therefore it is not important where informed traders trade.

Clyman, Allen, and Jaycobs (1997) find evidence of the relation between the liquidity of underlying market and the hedge behavior of the Dublin-based trading of FINEX's U.S. Dollar Index (USDX) contracts. They question the validity of using volume as a proxy for liquidity. The analysis shows that the USDX market in Dublin, a very low volume market, is far more liquid than its volume would indicate. They suggest that the market' liquidity is derived from hedging transactions in the market for the underlying securities. That implies that as long as it is possible to hedge a derivative position by taking offsetting positions in underlying markets, then even when the only link is the hedge activity of market makers, the liquidity of the underlying markets can be transferred to the derivative market, thereby causing it to be liquid even when it is not active.

\section{Option market Data}

The S\&P100 index options is traded at the CBOE in a continuous, open-cry auction among competitive market makers. There are two types of traders in the index options, floor brokers and market makers. Floor brokers bring public orders to the floor of the exchange and execute them at the best possible prices. All market makers of S\&P 100 index options trade only for their own account and they are free to seek out the best 
profit opportunities. A member is restricted to acting as either a broker or dealer for any particular security on any given day. Market makers have a responsibility to quote bid and ask prices in a way that contributes to price continuity and to the maintenance of a fair and orderly market, and as a result, provide liquidity to the market. In addition, an order book official is assigned to each class of option. These officials are employed by the exchange to display the highest bid and lowest ask prices and to record limit orders for later execution.

We use intraday transaction and quote data for S\&P 100 American call options from May 1993, as reported in the CBOE. The data set contains 180239 observations. Each day market makers trade options of at least three different times-to-maturity. Im May 1993, the maturity dates are May, June, July or August. ${ }^{5}$ In call option markets, trading tends to concentrate in near-to-maturity and close-to-the-money contracts, and thus more than $90 \%$ of active trading (more than 100 trades per day) are in series expiring in the current or immediately subsequent month.

We consider at-the-money options and out-of-the-money options. The shortest 10-day maturity options are excluded. Also, the quotes of zero bid prices are excluded because lower bounds may truncate the spread and bias it toward zero. Here, we also measure percentage spreads rather than absolute spreads. The former is the theoretically relevant price since discreteness in quotes means that the latter may not deal smoothly with options prices. Percentage spreads are measured as spreads divided by the midpoint of the bid and ask prices.

The percentage spread is a trading cost of a round trip transaction. It is the price

5 Since the expiration date is May $19^{\text {th }}, 1993$, the time-to-maturity consists of June, July and August after the expiration date. 
of immediacy a trader faces. Percentage spreads also reveal the costs of a market maker. Spreads result from the holding, order processing and informed trader costs. Holding costs are imposed by suboptimal portfolio positions to which the market makers commit. Order processing costs reflect the nature of the trading mechanism such as exchange fees, transfer taxes, etc. Finally, there is a cost from trading with informed traders. If the market is competitive, then a market maker's bid-ask prices must just compensate him for the costs of accepting the trade, and hence equal the trading cost.

Examining the location of transactions within the percentage spread provides one perspective on transaction costs. Transactions are categorized in three ways. Trades are 'at-the-spread' if the transaction price equals the bid or ask price. Transactions 'in-thespread' are those where the transaction price is in between the bid and ask prices. Trades 'out-of-the-spread' are those where the price is either lower than the bid price or higher than the ask price.

$<$ Table $1>$ and $<$ table $2>$ show the relation between transaction prices and bid-ask prices of the S\&P100 index call options: one for at-the-money options and one for out-ofthe-money options. Here, the bid and ask prices quoted right before the transactions are considered. That is, bid and ask prices are the most recent quotes before transactions occur. Lee and Ready (1991) argue that NYSE protocols cause quote revisions to be reported before the trades during these revisions; they therefore suggest that current trades be classified with the quote recorded 5 seconds prior. Such adjustment is not appropriate for trades on the $\mathrm{CBOE}$, in that the frequency of quote revision is greater, and thus using the most recent quote does not induce a bias. ${ }^{6}$

\footnotetext{
${ }^{6}$ Easley, O'Hara, and Srinivas (1997) also use the most recent quote for the trading classification for the same reason.
} 
According to $<$ table $1>$ and $<$ table $2>$ the distribution of call options transactions is skewed toward ask prices. That is, a large fraction of trade occur at the ask price and these trades are of a smaller size. S\&P100 index options seem to be predominantly 'buy', which means options are actively bought, rather than sold.

$75 \%$ of at-the-money options and $81 \%$ of out-of-the-money options are traded at the spread. This is a greater percentage than in NYSE trades. ${ }^{7}$ Two explanations are offered by Vijh (1990) and Easley, O'Hara and Srinivas (1998). If market makers behave competitively, then they offer the lowest acceptable quote at the outset, and simply are not be able to bargain. Alternatively, if informed trading is significant on the CBOE, trading at the quoted prices is a way in which the market markers protect themselves since informed trading may not be easily detected in the multiple market maker system.

The interesting case is that of the out-of-the-spread transactions. Here, the spread underestimates the transaction costs because traders face worse than posted prices for their transaction. That is, if the average of the bid and ask prices is a measure of the true value of options, then the cost of liquidity for a given trade can be estimated by the difference between the trade price and average of the bid and ask prices. The table also shows that out-of-the-spread trades have higher average volumes per transaction. The large trade volume may be the reason for these transaction costs if large trade has a bigger effect on prices than a small trade. When traders create large order flow imbalances and if market makers are unwilling to provide low cost liquidity to such an imbalance, the order flow imbalances may be satisfied at a price which does not reflect

\footnotetext{
7 Vijh (1990) shows the specialist structure for NYSE stocks has lower average spreads and a larger fraction of trades executed between the prevailing bid and ask prices than the CBOE competitive market maker structure for options on these stocks.
} 
the fundamental value. ${ }^{8}$

Another interesting fact is that in-the-spread transactions rarely happen. When the market maker quotes a wide spread there is less motive for a trader to trade with the market maker since he sees the spread as a cost which he has to pay. However, transactions may still occur in the spreads because in a multiple market maker system where market makers compete with each other, some of them are willing to offer liquidity to lower the cost for trades that they already intend to make. Also, within spread trades are most likely public limit orders that are hit by market makers or other public traders.

The principal difference between options and stocks is that an option contract can be distinguished by its moneyness and maturity terms. Moneyness is defined as the difference between the forward stock price and the strike price. Comparing at-themoney, out-of-the money, and in-the-money options gives insight into the cross-sectional perspective of percentage spreads and liquidity. Analyzing options percentage spreads in terms of moneyness, one would expect the more liquid market to have a lower percentage spread. In order to investigate how moneyness is related to percentage spreads, the piecewise linear spline method is applied to derive a nonlinear relation. The percentage spreads are a nonlinear function of logged moneyness. Here, moneyness is measured as the stock price divided the strike price, $S / \mathrm{Ke}^{-\mathrm{rt}}$, where $S$ is the stock price, $\mathrm{K}$ is the strike price, $r$ is the interest rate, and $t$ is the time to maturity. The determination of moneyness is based on the daily closing stock price. The piecewise linear spline model is set up as follows.

8 These traders may be informed and prefer to undertake a larger transaction outside the bid-ask spread. Or they may be block-trading institutions. 
Percentage Spread $=w+\beta_{0} \cdot \log ($ moneyness $)+\beta_{1} \cdot Z_{1}+\beta_{2} \cdot Z_{2}+\ldots+\beta_{n} \cdot Z_{n}+e$

where percentage Spread $=\frac{\text { bid }- \text { ask spread }}{\text { mid }- \text { quote as options price }}$

$$
\begin{aligned}
& \text { moneyness }=\frac{\text { forward stock price }}{\text { strike price }}=\frac{\mathrm{S}}{\mathrm{K} \cdot \mathrm{e}^{-\mathrm{rt}}} \\
& \log \text { (moneyness) } \in[\mathrm{a}, \mathrm{b}]^{9}{ }^{9} \\
& \text { a : minimum of } \log \text { (moneyness) } \\
& \mathrm{b}: \text { maximum of } \log \text { (moneyness) } \\
& \mathrm{a} \leq\left[\mathrm{C}_{1}, \mathrm{C}_{2}, \mathrm{C}_{3}, \ldots \mathrm{C}_{\mathrm{n}}\right]<\mathrm{b} \\
& \mathrm{Z}_{\mathrm{i}}=\log \text { (moneyness) }-\mathrm{C}_{\mathrm{i}} \quad \text { if } \log \text { (moneyness) }>\mathrm{C}_{\mathrm{i}} \text {, } \\
& \mathrm{Z}_{\mathrm{i}}=0 \quad \text { otherwise }
\end{aligned}
$$

The result of an application of this method is presented in <figure 1>. It shows that out-of-the-money options have bigger percentage spreads than in-the-money options and that at-the-money options percentage spreads are the lowest. This interesting feature allows one to investigate the prediction of the asymmetric information model that the more liquid market will have the smaller percentage spread and the prediction of the derivative-hedge model that the liquidity of the derivative market depends on whether a

9 Including out-of-the money and at-the-money options the minimum moneyness is 0.941437 while 1.01210 is its maximum. Therefore, the logged moneyness spans from -0.06035 to 0.012114 and these two numbers correspond to $a$ and $b$ in the spline regression. In order to get spline regression, we subsample data using the 10-percentile cumulative density of logged moneyess. $C_{1}$ is the number for $10 \%$ of logged moneyness, while $C_{9}$ is the number for $90 \%$ of logged moneyness. 
market maker in the option market can perfectly hedge his position with underlying stocks.

A comparison of $<$ table $1>$ and $<$ table $2>$ shows that out-of-the-money options have a bigger average volume per transaction than at-the-money-options while the former market is less active measured in terms of the number of transactions. According to the asymmetric information theory, if informed traders use option markets as their trading venue, then out-of-the-money options may be preferred for informed trading since an informed trader would profit more by using more leveraged contracts. The bigger percentage spread of out-of-the-money options may imply the existence of informed traders in that market. The widely recognized fact that at-the-money options are traded heavily may also explain why the at-the-money options has the lowest percentage spread. One possible explanation is that liquidity traders prefer at-the-money options for portfolio management. If volume, measured by number of transactions, is used as a proxy for liquidity, the heavy trading and smaller percentage spreads in this market may suggest that the at-the-money option market is more liquid than the out-of-the-money option market.

The relationship between the bid-ask spread and trading volume may take two forms in an asymmetric information framework. First, the proportion of informed traders may be higher for thinly traded contracts. This implies a negative correlation between the bid-ask spread (or the percentage spread) and trading volume holding the size of the transaction constant. Second, the proportion of informed trading may increase if informed trading is positively correlated with the size of the transaction. ${ }^{10}$ In this case,

\footnotetext{
${ }^{10}$ Thus, in intertemporal asymmetric information models a large average trade size suggests the presence of informed traders leading to a wider spread. On the other hand, from a cross sectional perspective, a
} 
there will be a positive correlation between volume and the bid-ask spread (or the percentage bid-ask spread) holding the number of transactions (per unit time) constant. According to Easley, Kiefer, O'Hara, and Paperman (1996) the probability of informed trading is low for frequently traded stocks. The proportion of informed traders is likely to be smaller for a frequently traded stock even with a higher frequency of information events and a consequent higher arrival rate of informed traders. This information arrival rate will not offset the effect of a higher arrival rate of uninformed traders. Large spreads in infrequently traded stocks can, therefore, be explained by the asymmetric information model. In this case, out-of-the-money options may have a higher probability of informed trading since those options are traded infrequently and are more leveraged in comparison with at-the-money options. ${ }^{11}$

An alternative explanation is that these percentage spreads are determined by the hedging costs of the market makers. Rather than holding exposed positions the market makers could continually delta hedge their position. If the underlying market is highly liquid then the spread in the option market would be determined by the liquidity in the underlying security market and the hedge ratio of the asset. Here, the liquidity of the atthe-money and out-of-the-money option market are determined by the same underlying assets, the S\&P100 index. Therefore the different percentage spreads of at-the-money options and out-of-the-money options may imply that delta hedging in each market is not perfect, since it is more difficult for the market maker to hedge his position in out-of-themoney options which have a bigger percentage hedge ratio. In this case, the at-the-

\footnotetext{
large volume of trades (large number of transactions) also corresponds to greater liquidity, and this increased liquidity should work to narrow spreads

is This analysis is supported by the argument in Neal (1992) that a sufficiently high trading volume, measured as the number of transactions could reduce the bid-ask spread to the minimum percentage spread.
} 
money market may have smaller percentage spreads compared with the out-of-money market. If the underlying security market is liquid then the difference in volume in each option should not matter. However, if a perfect hedge is not possible because of an illiquidity in underlying market, then the option market activity measured as the average volume per transaction may be significant in explaining the difference in percentage spreads. Therefore, this cross-sectional analysis may give evidence of imperfect hedges.

\section{Static Model}

In order to model spreads in S\&P100 index options, we first consider the static model. In the static model the option percentage spreads in the static model are explained by moneyness, time to maturity, option prices, volatility and the delta hedge ratio. Moneyness, time to maturity and options prices are included to capture the main characteristics of option markets while volatility and the delta hedge ratios are used to measure the relation between options and their underlying markets and to evaluate these market microstructure theories. With that in mind, we adopt the following model, in which the squared terms and cross terms are included to capture the nonlinearity of percentage spreads.

$$
\begin{aligned}
& \text { Percentage spread }=\beta_{0}+\beta_{1}[\text { call price }]+\beta_{2}[\text { moneyness }]+\beta_{3}[\text { timeto maturity }] \\
& +\beta_{4}[\% \text { delta }]+\beta_{5}[\text { implied volatility }]+\beta_{6}[\text { moneyness }]^{2}+\beta_{7}[\text { timeto maturity }]^{2} \\
& +\beta_{8}[\text { moneness } \cdot \text { timeto maturity }]+\beta_{9}[\text { moneyness } \% \text { delta }]+\varepsilon_{s}
\end{aligned}
$$


where percentage spreads $=\frac{\text { bid }- \text { ask spread }}{\text { call options price }}$

call options price $=$ mid-quote of bid-ask spread

moneyness $=\frac{\text { stock price }}{\text { strike price }}=\frac{S}{\mathrm{~K} \cdot \mathrm{e}^{-\mathrm{rt}}}$

$\%$ delta $=\frac{\Delta \mathrm{C}}{\Delta \mathrm{S}} \cdot \frac{\mathrm{S}}{\mathrm{C}}$

where $\mathrm{S}=$ stock price, $\mathrm{C}=$ call price, $\mathrm{K}=$ strike price,

$$
r=\text { interest rate, } t=\text { time to maturity }
$$

Using moneyness measured as the forward stock price divided by the strike price, we expect that the more out-of-the-money is the option, the bigger will be the percentage spread since those options provide the most leverage. It is consistent with the crosssectional examination of $<$ figure $1>$.

If bid and ask prices are based on full public information and if they are symmetrically distributed about the true option value, then the average of the bid and ask prices is a measure of the true option value. The option price measured as a mid-quote of the spread may have a positive relation to absolute spreads. CBOE tick-size rules may be an explanation for this possible positive relation since more expensive options have larger minimum spreads. ${ }^{12}$ This positive relation can be explained with inventory models because costs incurred by market makers may be positively related to the price of options traded, in that higher priced options imply greater changes in inventory value.

12 Options with prices of $\$ 3$ or more have tick sizes of $\$ 1 / 8$, leading to a spread of at least $\$ 1 / 8$, 
Time to maturity may affect the percentage spread because of the exercise notification procedure for the S\&P100 index options which result in horizon specific hedge demand. ${ }^{13}$

The volatility of stock returns is considered following the argument of Copeland and Galai that the spread increases with the volatility of the underlying stock. Implied volatility is used. ${ }^{14}$ At-the-money options of greater than ten-day time-to-maturity are considered for the implied volatility.

The hedge ratio, percentage delta, is incorporated into the static model in order to evaluate the asymmetric information and derivative hedge theories. If the hedge ratio is significant in explaining the percentage spreads in option market, then we can see the importance of the role of hedging since it considers the elasticity of options prices with respect to the underlying stock prices. It is expected to have a positive correlation with percentage spreads because options with the biggest percentage deltas are the options whose returns are the most sensitive to changes in the S\&P100 index. ${ }^{15}$

The market maker as a writer of a call options needs to hedge his position with a long share position. If the percentage delta is higher then the market maker would increase the percentage spread since he may find it costly to fully hedge his position. Biais and Hillion (1990) show that inventory risk from hedging is related to spreads. It

whereas options of under $\$ 3$ have tick sizes and minimum spread of $\$ 1 / 16$.

13 The options payoffs are determined by the index level at the end of the exercise day. The writer of the option does not know that the options have been exercised until the next day. By this time, the index value could have changed substantially. Therefore, index options impose price risks on market makers who write the options because covered positions are costly to maintain.

${ }^{14}$ It is the volatility implied by the option price observed in the market and the value when the stock price, strike price, interest rate and time-to maturity are substituted into the Black-Scholes formula.

${ }^{15}$ Cox and Rubinstein (1985) show that out-of-the-money options have the highest elasticity with respect to the index. 
may be explained in asymmetric information theory even though the theory itself does not explicitly address the relation between stock volatility and percentage spreads of options. If the out-of-the-money market is a venue for informed trading and out-of-the money options have bigger percentage spreads, then the percentage spread and percentage delta would have a positive relation. Here, percentage delta is computed using implied volatility of at-the-money options of greater than ten-day time-to maturity.

\section{Dynamic Model}

To explain the dynamics of the bid-ask percentage spread, we consider the effect of trading intensity in the option markets on their spreads. For this purpose, the average volume of a pre-determined number of transactions and the duration between transactions are considered. Considering these relations, we propose a dynamic model for bid-ask percentage spread of the following form.

Percentage spread $=$ Static Model $+\beta_{10}[$ duration $]+\beta_{11}[\text { duration }]^{2}+\beta_{12}[$ volume $]+\varepsilon_{D}$

where, duration $=$ average duration for 10 transactions volume $=$ average volume for 10 transactions

In order to understand the relation between trading intensity and percentage spreads, average duration and average volume are calculated using the last 10 transactions of the appropriate type. 
In Easley and O'Hara's model, the market maker increases the bid-ask percentage spread following a large transaction since informed traders prefer a larger size of transaction. Hence, for a given number of transactions in each option market, regardless of its moneyness, the bid-ask percentage spread will be wider following a large transaction if each option behaves as an Easley and O'Hara asset. That is, the market maker will increase the percentage bid-ask spread when there is a high average transaction volume given the number of transactions, concluding that these transactions are initiated by informed traders. If this hypothesis were correct then the average transaction volume would be positively related to percentage spreads. However, in a perfect hedge world, where the market maker can hedge his position through the liquidity of the underlying market, then percentage spreads in the option market depend on activities in underlying markets rather than those in option markets. Then the volume in the option market itself may not be a good proxy for liquidity in the option markets. It implies that average transaction volume may enable us to evaluate those two theories.

The examination of volume also allows us to address the price discovery between two markets, option market and its underlying security market. According to Easley, O'Hara and Srinivas (1998) option volume conveys information and as a result, option markets are the place where we can predict future prices of stocks as well as of options. However, in the derivative hedge model, option volume as a proxy for option market activity may not play a significant role in determining spreads in the option market, since liquidity in the underlying market can be tapped through the hedging behavior of market makers. Therefore, in this case, there may be no causality from options volume to stock prices. 
Short transaction duration implies that the market is moving fast, possibly showing the presence of informed traders. If informed traders come into possession of news, then they will enter the market. Therefore, the market maker will increase the percentage spread leading to a negative relation between duration and spread. On the other hand, in an inventory model, market activities are negatively related to spreads because of the market marker's inventory risk. ${ }^{16}$ However, in a derivative hedge theory, duration between transaction should not affect the percentage spread in the option market because the market marker's perfect hedging can make option market activity independent of percentage spreads. Therefore the relation between a fast moving market and its large percentage spreads would be predicted by asymmetric information theory while inventory models would predict big spreads in slow markets. Spreads will be unrelated to duration if the underlying market provides a perfect hedge. In order to examine those arguments, we add the squared term of duration. If traditional theories, asymmetric information and an inventory model, are right, then percentage spreads may be U-shaped with respect to durations, with extremes having bigger spreads.

In addition to estimate a dynamic model, we perform the cubic spline regression of percentage spreads on duration. <Table $3>$ shows that duration has an asymmetric distribution. The median duration is 139 seconds for the at-the-money options and 473 seconds for the out-of-the-money options. That shows that the short duration consists of almost $50 \%$ of data for the at-the-money options and that the at-the-money option market

16 By examining options in a cross section perspective George and Longstaff (1993) show that spreads are larger for options that trade less actively. Without considering the effects of adverse selection, they report that a $\$ 1 / 16$ increase in the spread increases the average time between trades by 2.91 minutes for calls and 2.90 minutes for puts. 
moves faster than the out-of-the-money option market. ${ }^{17}<$ Figure $2>$ to $<$ figure $4>$ fit percentage spreads on log normalized duration to capture the U-shaped percentage spreads for at-the-money, out-of-the-money and all options combining both. ${ }^{18}$

\section{Cross-market model}

Because all of the these options are written on the same underlying stocks, percentage spreads in one options may depend on market activities in cross-option markets as well as in the underlying stock market. When a market maker quotes a spread for one options, his behavior might be conditioned on information derived from the trading activity of other options as well as of the underlying market.

In order to incorporate cross-market activities, we add the cross-option market activity measured as an inverse of cross-options duration. That is, for at-the-money options percentage spreads we include the effect of out-of-the-money option market activities. If the inverse of the out-of-the-money option duration is large, which means that the out-of-the-money option markets is active, then the market maker may receive a signal of informed trading in these markets. As a result, he may change quotes to increase the percentage spreads for at-the-money as well as for out-of-the-money options.

17 The asymmetry of duration distribution leads us to use two criteria, the percentiles and the unit-time interval for the cubic spline regressions. $25,20,10$ and 5 percentiles of duration are used for the regressions. The unit interval criterion includes every 30, 60, 120, 180, 240 and 360 seconds of data. We still find almost the same minimum percentage spread in the cubic spline regression for each options regardless of subsampling methods. Here we report the result using percentiles subsampling.

${ }_{18}$ The minimum of the fitted percentage spreads from the cubic spline regressions corresponds to 1111 seconds for the at-the-money options and 54 seconds for the out-of-the-money options, and 64 seconds for all options combining at-the-money options and out-of-the-money options. 
The at-the-money option market activity may have similar effects on the behavior of the market maker in deciding the out-of-the-money option's spreads.

According to derivative hedge theory, the spreads in derivative markets are determined by the liquidity of the underlying markets. If the market maker cannot perfectly hedge his position with underlying assets, then the spread in the option markets reveals the presence of informed trading in underlying markets that are illiquid. In order to consider this argument, we include the spreads in underlying markets in the crossmarket model. If options can be traded at the right price, the index futures will be the best substitutes that an index options trader can find. Traders in S\&P100 index option markets are always searching for an acceptable substitute for the underlying basket of 100 stocks. A future contract on this index would be an ideal substitute but, unfortunately, one does not exist. Therefore, we use an average of previous one minute percentage spreads of 21 actively traded stocks on NYSE for the underlying market liquidity in order to examine the relation between the option markets and their underlying markets. This result tests the derivative-hedge theory. The underlying stocks are IBM, General Motors, Disney, Johnson and Johnson, Philip Morris, Boeing, Eastman Kodak, Exxon, Proctor and Gamble, Walmart, Dupont, McDonald, JP Morgan, Minnesota MNG \& MFG, Merck, AT\&T, Westinghouse Electric, Hewlett Packard, Chevron, Utd Technologies, and Good Year. They are chosen since they are components of the DJIA. The cross-market model is as follows.

Percentage spread $=$ Dynamic Model

$$
+\beta_{13}[\text { cross }- \text { options markets }]+\beta_{14}[\% \text { spread of stocks }]+\varepsilon_{c}
$$


where, cross-option markets = cross-option market activity

$\%$ spread of stocks = average percentage spreads of underlying stock markets

Here, cross-option market activity is measured as the inverse of duration for past 10 transactions of cross-options. For example, in order to explain the percentage spreads of at-the-money options the inverse of the total time elapsed during 10 out-of-the money transactions is used. \% spread of stocks as an independent variable is measured as the average of the previous one minute average percentage spreads in 21 underlying stock markets.

\section{Empirical Results}

The analysis of S\&P 100 index options is presented in three different models, the static, dynamic, and cross-market model. Percentage spreads are modeled for at-themoney options and out-of-money options. We also consider the whole market that combines at-the-money and out-of-money options. The empirical results are reported in $<$ table $4>$ to $<$ table $6>$.

In a static model, we consider the variables such as moneyness, option price, time to maturity, volatility and percentage delta. The tables show that percentage spreads are a decreasing function of moneyness. Out-of-the-money options have bigger spreads than at-the-money options.

The coefficient on the option price has a negative sign. However, it is not 
surprising, because the model uses the percentage spread. Any measurement error in the price such as inevitably arises from discreteness, will lead to negative correlation.

The coefficient of time to maturity is negative because the near-maturity option is more likely to be exercised and as a result it may be difficult for the market maker to maintain a hedged position. Or there may be a greater probability of a trader who prefers a cheap options is informed.

Volatility and the percentage delta have positive signs as expected. If the stock price is more volatile and the elasticity of the options price with respect to the stock price is bigger, then a market maker will widen the percentage spread. This result supports the derivative hedge theory since volatility and percentage deltas are related to the underlying market's liquidity and this relationship is what matters in that theory. If a market maker cannot tap the liquidity from the underlying market then the market maker may increase spreads to compensate for the risk of exposing his positions. The significance of percentage delta supports the derivative hedge theory.

In a dynamic model, variables to measure the options trading intensity are considered. An interesting result is that options transaction volume is not a significant determinant of option market percentage spreads, challenging the validity of volume as a proxy for liquidity. ${ }^{19}$ This is quite different from the analysis of the stock market that reports bigger spreads with bigger size per trade. Our result supports the derivative

19 Vijh (1990) also provides the evidence of insignificant trade volume in explaining the spreads of CBOE options. He shows that the information content of option spreads is not related to trade volume. Neal (1992) also obtains similar results for the relation between spreads and average size of transaction of CBOE and AMEX options. He uses 3 different measures of spreads: the quoted spread, the current spread, and the effective spread. The positive trade size coefficients for the quoted spread and the current spread specifications are consistent with the model by Easley and O'Hara. However, in the effective spread specification, the coefficient is negative but more than one standard error below zero. 
hedge theory that the option market volume does not affect option spreads if a market maker can find a liquid underlying market for his hedge.

However, we find that the duration of the past 10 transactions does affect option market percentage spreads. It has a negative relationship in levels but there is a positive relationship with squared duration. This implies that percentage spreads are a U-shaped function of duration, which is consistent with the asymmetric information models at short duration and the inventory risk model at long duration. These results would not be observed if the underlying market provided a perfect hedge. The interesting aspect of this result is that we can calculate the duration for the minimum percentage spreads. According to the table the duration is 148 seconds, ${ }^{20}$ which is close to the median of duration for the at-the-money options. (See table 3.) Therefore, the O'Hara and Easley asymmetric information world explains half of the data for duration, which implies that informed trading in option markets might happen frequently.

The results of volume and duration have interesting implications of the existence of informed trading and the market marker's hedging behavior in the CBOE. By finding that transaction volume is not related to option spreads, Vijh (1990) argues that informed trading is not significant in the CBOE. However, our distribution of duration shows that the informed trading may prevail in the CBOE. On the other hand, our finding that volume has insignificant explanatory power over option spreads underlines the importance of the market maker's hedge behavior. Even with the existence of informed

20 The duration for the minimum percentage spreads from the dynamic model is calculated as exponential value for the coefficient of duration divided by twice the coefficient of squared duration. Here exponential function is taken since in dynamic model, we consider logged duration and logged squared duration. However, it is not same as the duration for minimum value of fitted percentage spreads in cubic spline regression since they are obtained from the different estimation. 
traders in the $\mathrm{CBOE}$, the market marker is no longer subject to the risk of informed trading if he can neutralize his positions through hedges.

In the cross-market model, the cross-option market activity has an interesting interpretation. The market activity of out-of-the-money options is a significant determinant of at-the-money option spreads while the market activity of at-the-money options is not a significant determinant of the spreads of out-of-the-money options. These results can be motivated using cross sectional analysis. As we see in <figure 1>, out-of-the-money options have bigger spread than at-the-money options. The active outof-the-money option market may send a signal of the presence of informed trading to market makers who, as a result, increase the spread for at-the-money options as well as for out-of-the-money options.

An interesting result is the role of average percentage spreads of 21 underlying stocks on the percentage spreads of options. In $<$ table $4>$ it has a positive effect as is expected in the derivative-hedge model. The percentage spreads in underlying stocks reveals their liquidity and that suggests this is transferred to the option markets directly by the market makers' hedge behavior. This result is consistent with the insignificance of average volume in the dynamic model and seems to support the derivative-hedge model.

Volatility, percentage delta, average volume for past 10 options transactions, and the percentage spreads for the underlying market are included in order to evaluate the importance of the derivative hedge theory. The empirical results show that the derivative-hedge model is supported by those variables even though the overall empirical results may also be interpreted from the perspective of traditional market microstructure theories. 
We interpret these mixed results to mean that the option market maker is only able to imperfectly hedge his position in the underlying market. If a market maker can not hedge his position perfectly, then the option market activity itself may affect the market maker's quoting behavior. That is, a perfect hedge would make option market spreads depend only on the liquidity of the underlying stock markets while the illiquidity in the underlying asset leads to an imperfect hedge in the option markets and as a result, the option market activity itself still may have an effect on the spreads of options.

The finding of insignificant option volume casts doubt on the price discovery argument between stock and option markets (Easley, O'Hara, and Srinivas (1998)) since the informed options trading activity may be revealed in imbalances in the hedge positions in the market marker's accounts on the underlying asset. Asymmetric information costs in either market are naturally passed to the other market by market maker's hedging and therefore it is unimportant where the informed traders trade.

\section{Conclusion}

In this paper, we examine the impact of market activity on the percentage bid-ask spreads of S\&P 100 index options using transactions data. We propose a new market microstructure theory called the derivative hedge theory, in which option market percentage spreads will be inversely related to the option market maker's ability to hedge his positions in the underlying market, as measured by the liquidity of this underlying market. In a perfect hedge world, spreads arise from the illiquidity of the underlying market, rather than from inventory risk or informed trading in the option market itself.

We estimate three models to investigate various market microstructure theories. In 
the static model, option spreads are a function of moneyness, time to maturity, options prices, hedge ratios and volatility. The dynamic model includes time between trades or duration and average volume per transaction while the cross-market model adds crossoption market activity and spreads in the underlying market.

We find option market volume is not a significant determinant of option market spreads, which challenges the validity of volume as a proxy for liquidity or informed trading and supports the derivative hedge theory. Option market spreads are positively related to spreads in the underlying market, again supporting the theory. However, option market duration does affect option market spreads, with very slow and very fast option markets both leading to bigger spreads. Only the fast market result would be predicted by asymmetric information theory. Inventory models predict big spreads in slow markets. Neither would be observed if the underlying securities market provided a perfect hedge. We interpret these mixed results to mean that the option market maker is able to only imperfectly hedge his positions in the underlying securities market.

Our finding of insignificant options volume casts doubt on the price discovery argument between stock and option markets (Easley, O'Hara, and Srinivas (1998)). Asymmetric information costs in either market are naturally passed to the other market by market maker's hedging and therefore it is unimportant where the informed traders trade. 


\section{REFERENCES}

Amihud, Y. and H. Mendelson, 1980, Dealership Market: Market-Making with Inventory, Journal of Financial Economics 8, 31-53.

Anthony, J.H., 1988, The Interrelation of Stock and Options Market Trading-Volume Data, Journal of Finance 43, 946-961.

Back, K., 1993, Asymmetric Information and Options, Review of Financial Studies 6, $435-472$.

Bhattacharya, M., 1987, Price Changes of Related Securities: The Case of Call Options and Stocks, Journal of Financial and Quantitative Analysis 22, 1-15.

Biais, B. and P. Hillion, 1994, Insider and Liquidity Trading in Stock and Options Markets, Review of Financial Studies 7, 743-780.

Black, F., 1975, Fact and Fantasy in Use of Options, Financial Analysts Journal 31, 36$41,61-72$.

Chan, K., Y. P. Chung, and H. Johnson, 1993, Why Option Prices Lag Stock Prices: A Trading-Based Explanation, Journal of Finance 48, 1957-1967.

Clayman, D., C.S. Allen and R. Jaycobs, 1997, Liquidity without Volume: The Case of FINEX, Dublin, Journal of Futures Market 17, 247-277.

Copeland, T. and D.Galai, 1983, Information Effects and the Bid-Ask Spread, Journal of Finance 38, 1457-1469.

Easley, D. and M. O'Hara, 1987, Price, Trade Size, and Information in Securities Markets, Journal of Financial Economics 19, 69-90.

Easley, D., M. O'Hara and P.S. Srinivas, 1998, Options Volume and Stock Prices: Evidence on Where Informed Traders Trades, Journal of Finance 53, 431- 
465.

Easley, D., N.M. Kiefer, M. O'Hara and J.B. Paperman, 1996, Liquidity, Information, and Infrequently Traded Stocks, Journal of Finance 51, 1405-1436.

Fleming, J., B. Ostdiek and R.E. Whaley, 1996, Trading Costs and the Relative Rates of Price Discovery in Stock, Futures, and Options Markets, Journal of Futures Markets.

Foster, F.D. and S. Viswanathan, 1993, Variations in Trading Volume, Return Volatility, and Trading Costs: Evidence on Recent Price Formation Models, Journal of Finance 48, 187-211.

George, T. and F. Longstaff, 1993, Bid-Ask Spreads and Trading Activity on the S\&P 100 Index Options Market, Journal of Financial and Quantitative Analysis $28,381-397$

Glosten, L. and P. Milgrom, 1985, Bid, Ask, and Transaction Prices in a Specialist Market with Heterogeneously Informed Traders, Journal of Financial Economics $13,71-100$.

Grossman, S.J., 1988, An Analysis of the Implications for Stock and Futures: Price Volatility of Program Trading and Dynamic Hedging Strategies, Journal of Business 61, 275-298.

Harris, L.E., 1990, Liquidity, Trading Rules, and Electronic Trading Systems, Monograph Series in Finance and Economics, New York University.

Harvey, C. R. and R.E. Whaley, 1991, S\&P 100 Index Option Volatility, Journal of Finance 46, 1251-1261.

Hasbrouck, J. and G. Sofianos, 1993, The Trades of Market Makers: An Empirical 
Analysis of NYSE Specialists, Journal of Finance 48; 1565-1593.

Ho, T. and H. Stoll, 1983, Optimal Dealer Pricing Under Transactions and Return Uncertainty, Journal of Finance 38, 1053-1074.

Hull, J., 1993, Options, Futures, and Other Derivative Securities, Prentice Hall.

John, K., A. Koticha and M. Subrahmanyam, 1993, The Micro-Structure of Options Markets: Informed Trading, Liquidity, volatility, and Efficiency, Working Paper, New York University.

Kyle, A.S., 1985, Continuous Auction and Insider Trading, Econometrica 53, 1315-1336.

Lee, C. and M.J. Ready, 1991, Inferring Trade Direction from Intraday Data, Journal of Finance 2, 773-746.

Lee, C., B. Mucklow and M.J. Ready, 1993, Spreads, Depths, and the Impact of Earnings Information: An Intraday Analysis, Review of Financial Studies 6, 345374.

Madhavan, A. and S. Smidt, 1993, An Analysis of Changes in Specialist Inventories and Quotations, Journal of Finance 48, 1595-1628.

Manaster, S. and R.J. Rendleman, 1982, Options Prices as Predictor of Equilibrium Stock Prices, Journal of Finance 37, 1043-1057.

Mayhew, S., A. Sarin and K. Shastri, 1995, The Allocation of Informed Trading across Related Markets: An Analysis of the Impact of Changes of Equity-Options Margin Requirement, Journal of Finance 505, 1635-1654.

Neal, R., 1992, A Comparison of Transaction Costs between Competitive Market Maker and Specialist Market Structures, Journal of Business 65, 317-334.

O'Hara, M., 1995, Market Microstructure Theory, Oxford: Blackwell. 
Sheikh, A.M. and E.I. Ronn, 1994, A Characterization of the Daily and Intraday Behavior of Returns on Options, Journal of Finance 49, 557-580.

Stephen, J.A. and R.E. Whaley, 1990, Intraday Price Change and Trading Volume Relations in the Stock and Stock Options Markets, Journal of Finance 45, $191-220$.

Stoll, H.R. and R.E. Whaley, 1990, The Dynamics of Stock Index and Stock Index Futures Returns, Journal of Financial and Quantitative Analysis 25, 441468.

Stoll, H.R., 1989, Inferring the Components of the Bid-Ask Spread: Theory and Empirical Tests, Journal of Finance 44, 115-134.

Vijh, A.M., 1990, Liquidity of the CBOE Equity Options, Journal of Finance 45, 1157 1179. 
</ref_section> 


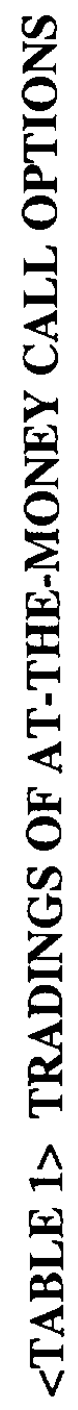

\begin{tabular}{|c|c|c|c|c|c|c|}
\hline $\begin{array}{l}\frac{\tilde{g}}{5} \\
\\
\end{array}$ & $\begin{array}{l}\stackrel{0}{0} \\
\stackrel{9}{9}\end{array}$ & $\stackrel{\partial}{\stackrel{g}{S}}$ & $\stackrel{\circ}{\stackrel{\infty}{\infty}}$ & 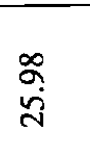 & 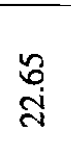 & \\
\hline $\begin{array}{l}\frac{n}{\vec{a}} \\
\frac{\vec{d}}{2} \\
5 \\
5\end{array}$ & o̊ & $\stackrel{m}{0}$ & $\check{0}$ & $\stackrel{m}{0}$ & $\stackrel{\check{O}}{0}$ & \\
\hline 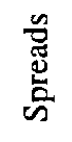 & $\overline{\overline{0}}$ & $\overline{\overline{0}}$ & ড্ড & $\overline{\bar{O}}$ & $\frac{O}{0}$ & \\
\hline \multirow{2}{*}{ 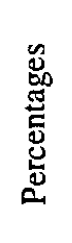 } & $\stackrel{+}{m}$ & 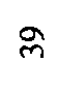 & $N$ & $\simeq$ & $\underline{m}$ & 음 \\
\hline & $m$ & & $N$ & $\approx$ & & 8 \\
\hline \multirow{2}{*}{ 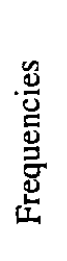 } & 总 & 产 & $\stackrel{m}{m}$ & 岕 & 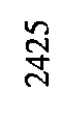 & 영 \\
\hline & స్ & & 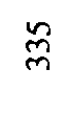 & $\underset{\&}{\stackrel{m}{\sigma}}$ & & $\begin{array}{l}\text { 웜 } \\
\text { a }\end{array}$ \\
\hline 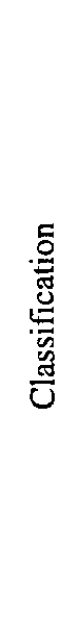 & 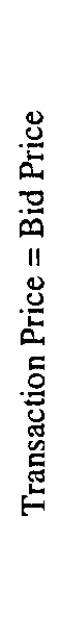 & 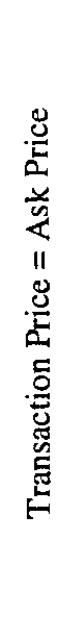 & 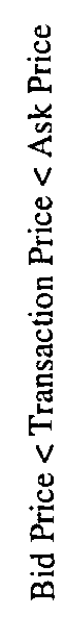 & 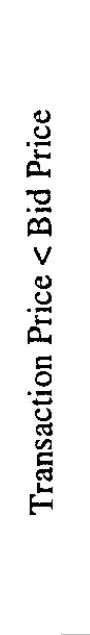 & 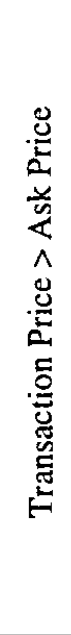 & \\
\hline 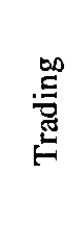 & 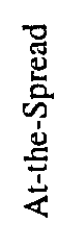 & & 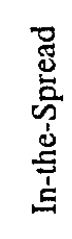 & 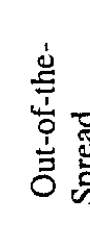 & & \\
\hline
\end{tabular}




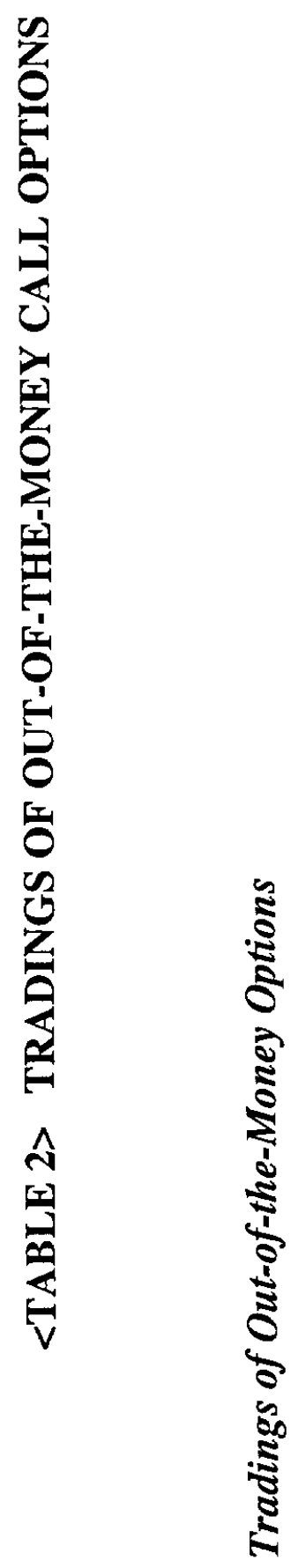

\begin{tabular}{|c|c|c|c|c|c|c|}
\hline 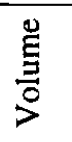 & $\begin{array}{l}F \\
\text { ¿ें }\end{array}$ & $\begin{array}{l}\stackrel{8}{0} \\
\underset{\sim}{\pi}\end{array}$ & 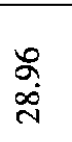 & $\begin{array}{l}\text { ஸे } \\
\text { ஸे }\end{array}$ & $\begin{array}{l}\text { సి } \\
\text { సి. }\end{array}$ & \\
\hline $\begin{array}{l}\frac{n}{\mathrm{~J}} \\
\frac{\mathrm{d}}{0} \\
0 \\
0\end{array}$ & oे & $\stackrel{8}{0}$ & $\stackrel{m}{0}$ & ¿্. & $\ddot{0}$ & \\
\hline 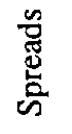 & $\stackrel{\infty}{\circ}$ & $\stackrel{\infty}{\circ}$ & $\stackrel{5}{0}$ & $\stackrel{\infty}{\circ}$ & $\stackrel{5}{0}$ & \\
\hline \multirow{2}{*}{ 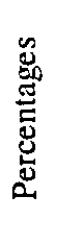 } & $\stackrel{i}{m}$ & $\stackrel{g}{\dot{y}}$ & $\stackrel{i}{\mathrm{~N}}$ & : & $\stackrel{0}{\infty}$ & $\stackrel{8}{0}$ \\
\hline & $\underset{\infty}{n}$ & & $\stackrel{\vec{i}}{\mathrm{~d}}$ & $\overrightarrow{\underline{a}}$ & & 8 \\
\hline \multirow{2}{*}{ 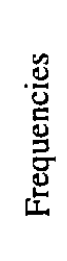 } & $\stackrel{\infty}{\stackrel{2}{\approx}}$ & 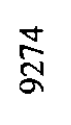 & $\stackrel{\circ}{\stackrel{\circ}{\sigma}}$ & $\stackrel{\infty}{\stackrel{\infty}{n}}$ & $\stackrel{8}{\Xi}$ & 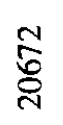 \\
\hline & 貉 & & 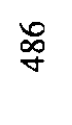 & $\frac{\bar{N}}{m}$ & & $\begin{array}{l}\mathbb{N} \\
\stackrel{\sim}{~}\end{array}$ \\
\hline 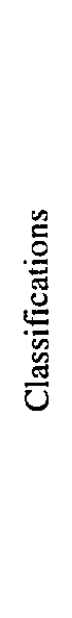 & 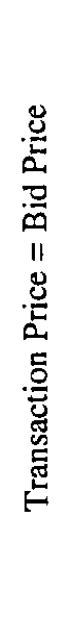 & 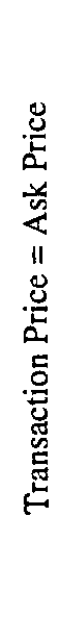 & 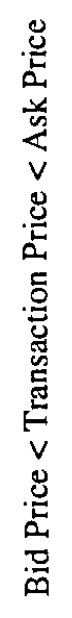 & 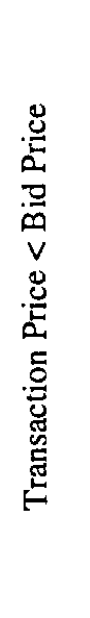 & 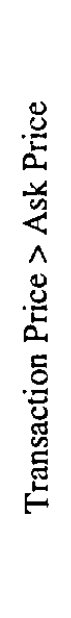 & \\
\hline 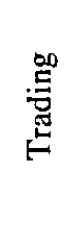 & 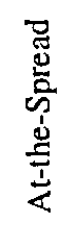 & & 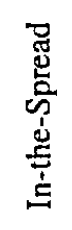 & 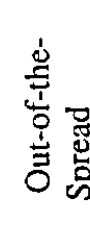 & & 哭 \\
\hline
\end{tabular}


< Figure $1>$ Percentage Spreads and Logged Moneyness

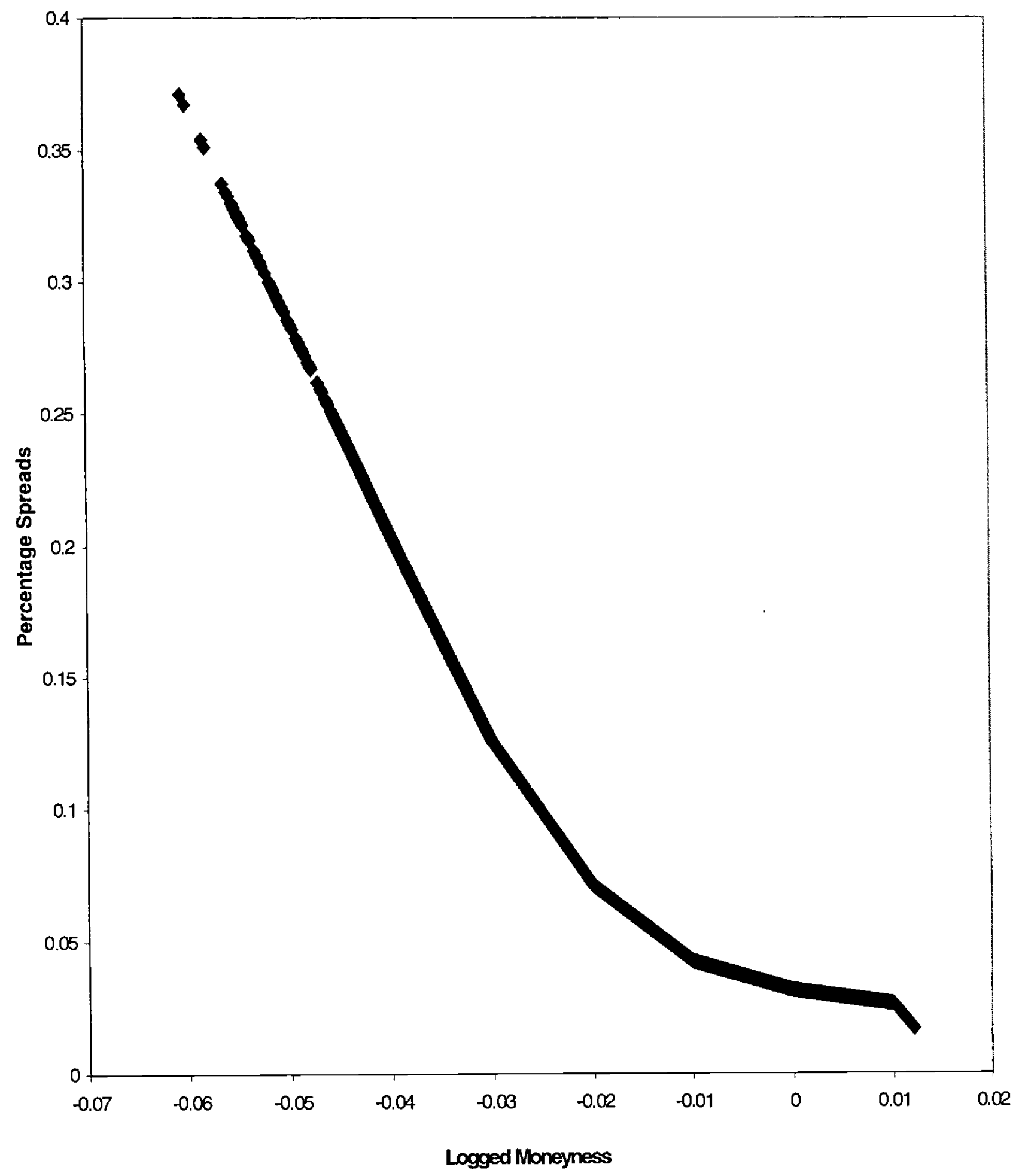

$<A-3>$ 


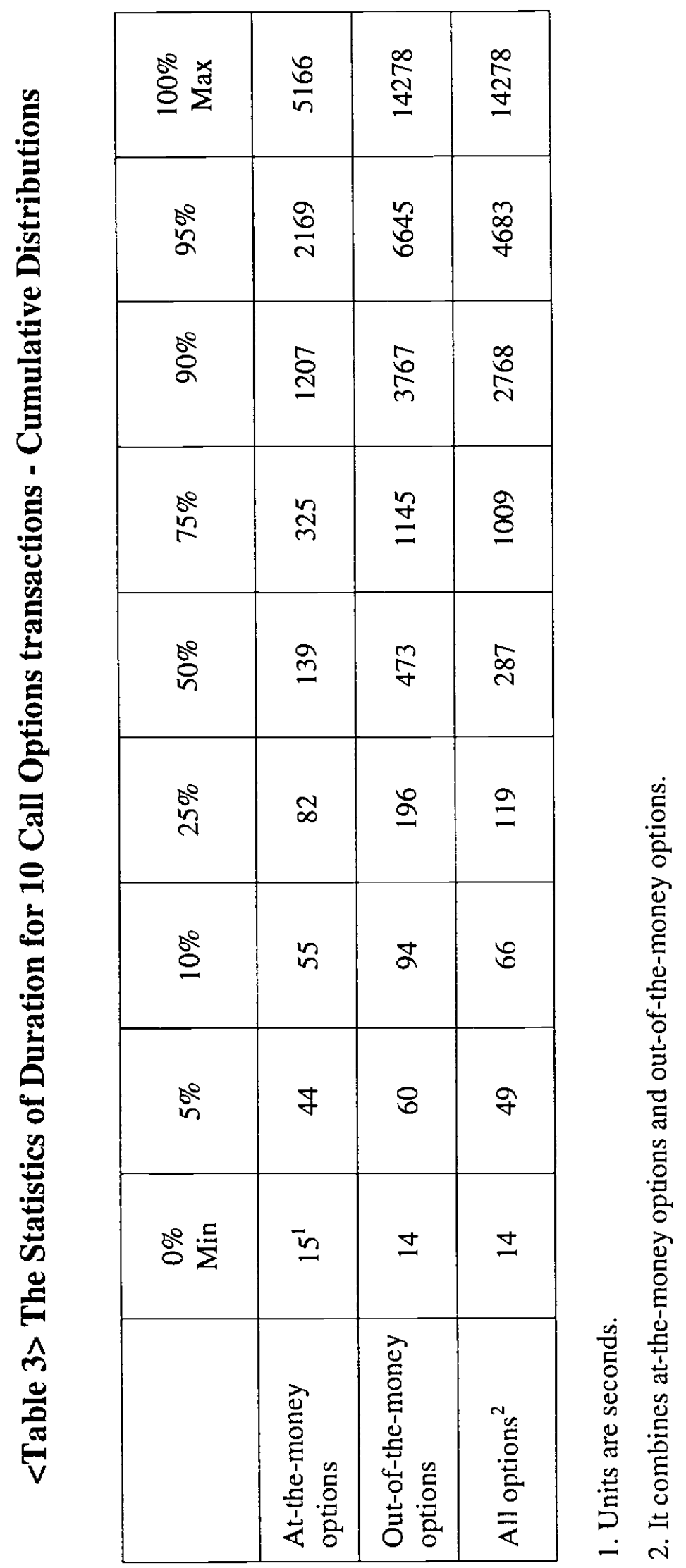




\section{< Figure 2 > Percentage Spreads and Durations \\ (At-the-Money Options)}

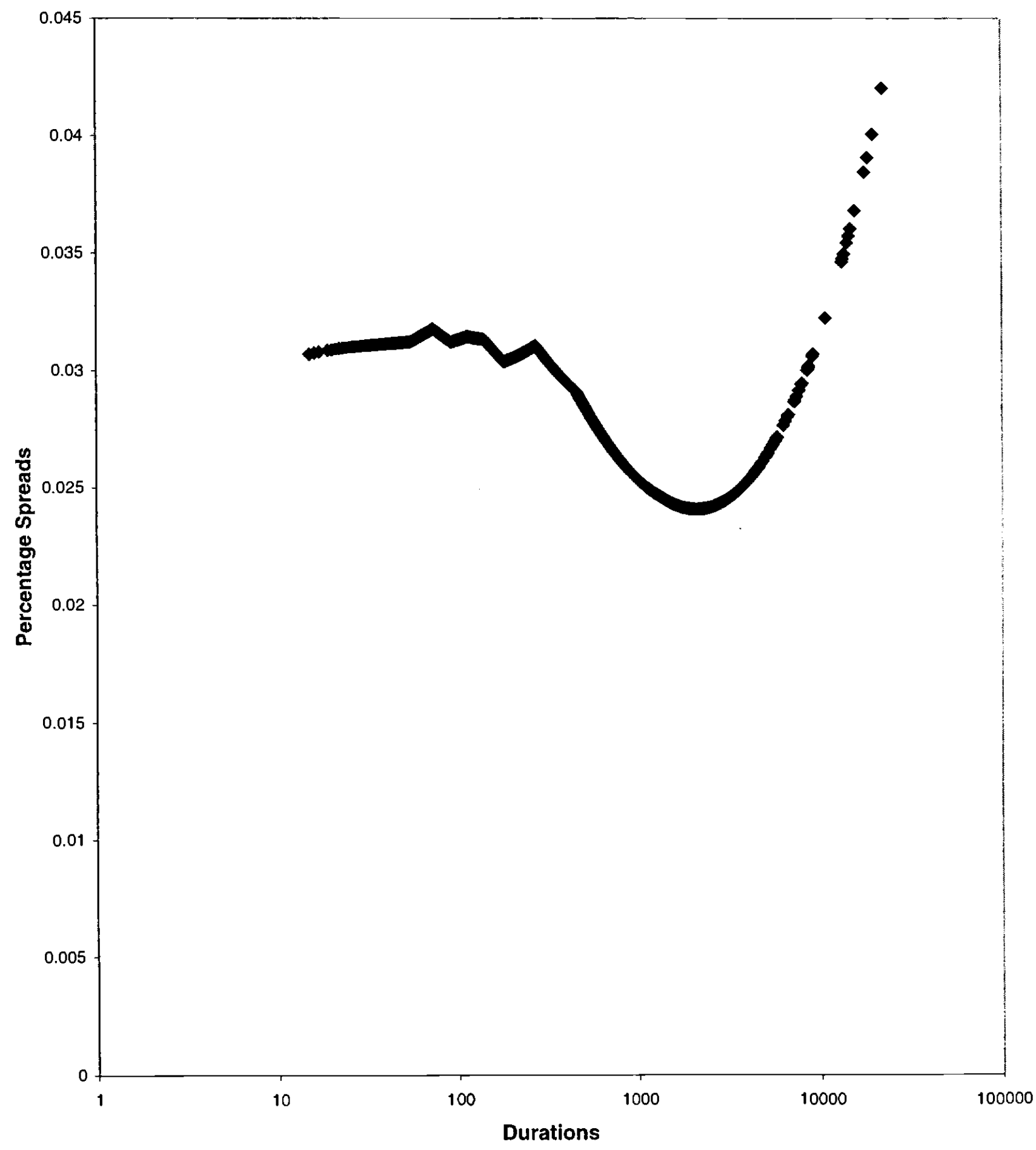


< Figure 3 > Percentage Spreads and Durations

(Out-of-the-Money Options)

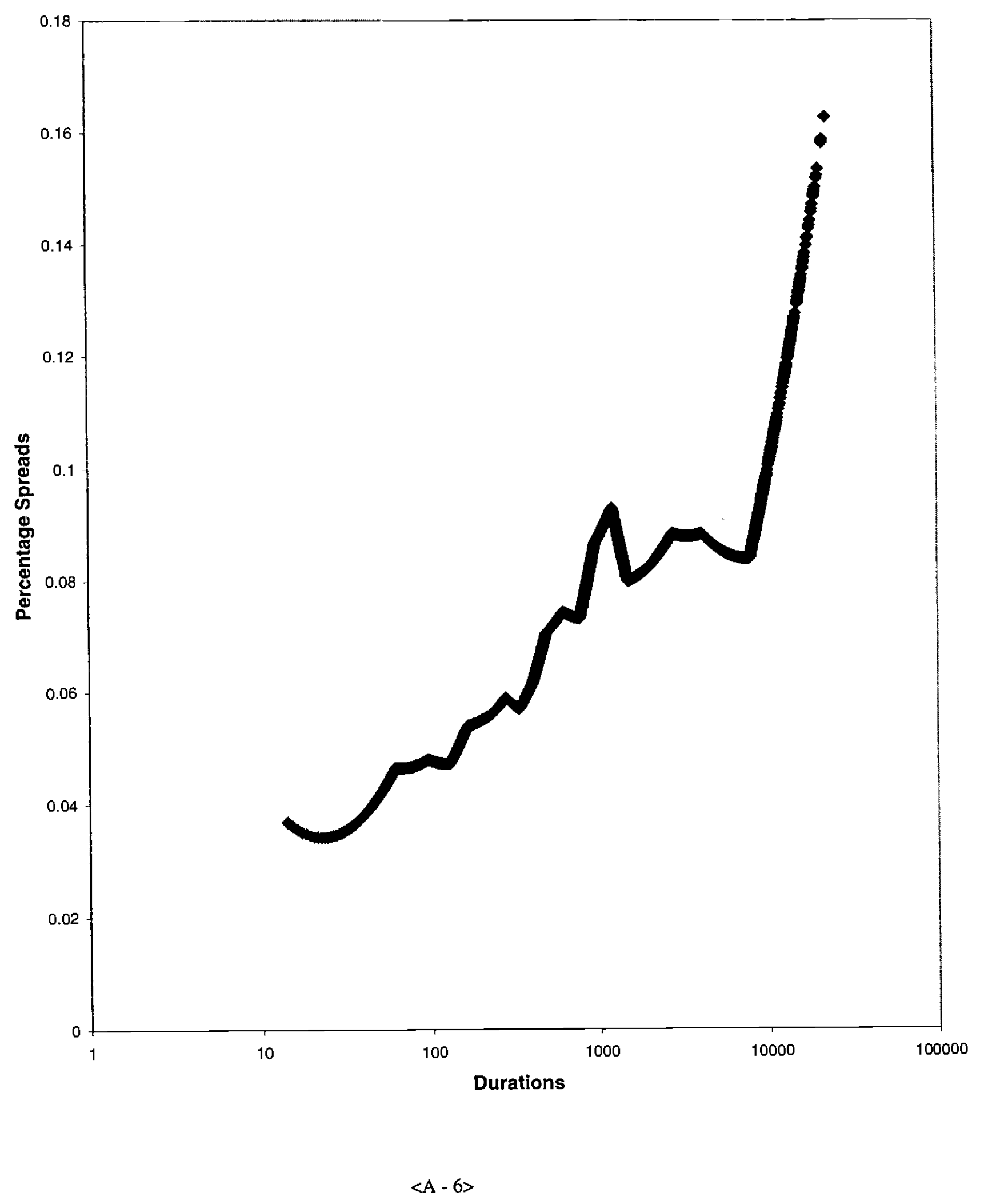




$$
\text { < Figure 4 > Percentage Spreads and Durations }
$$

(All options combining at-the-money and out-of-the-money options)

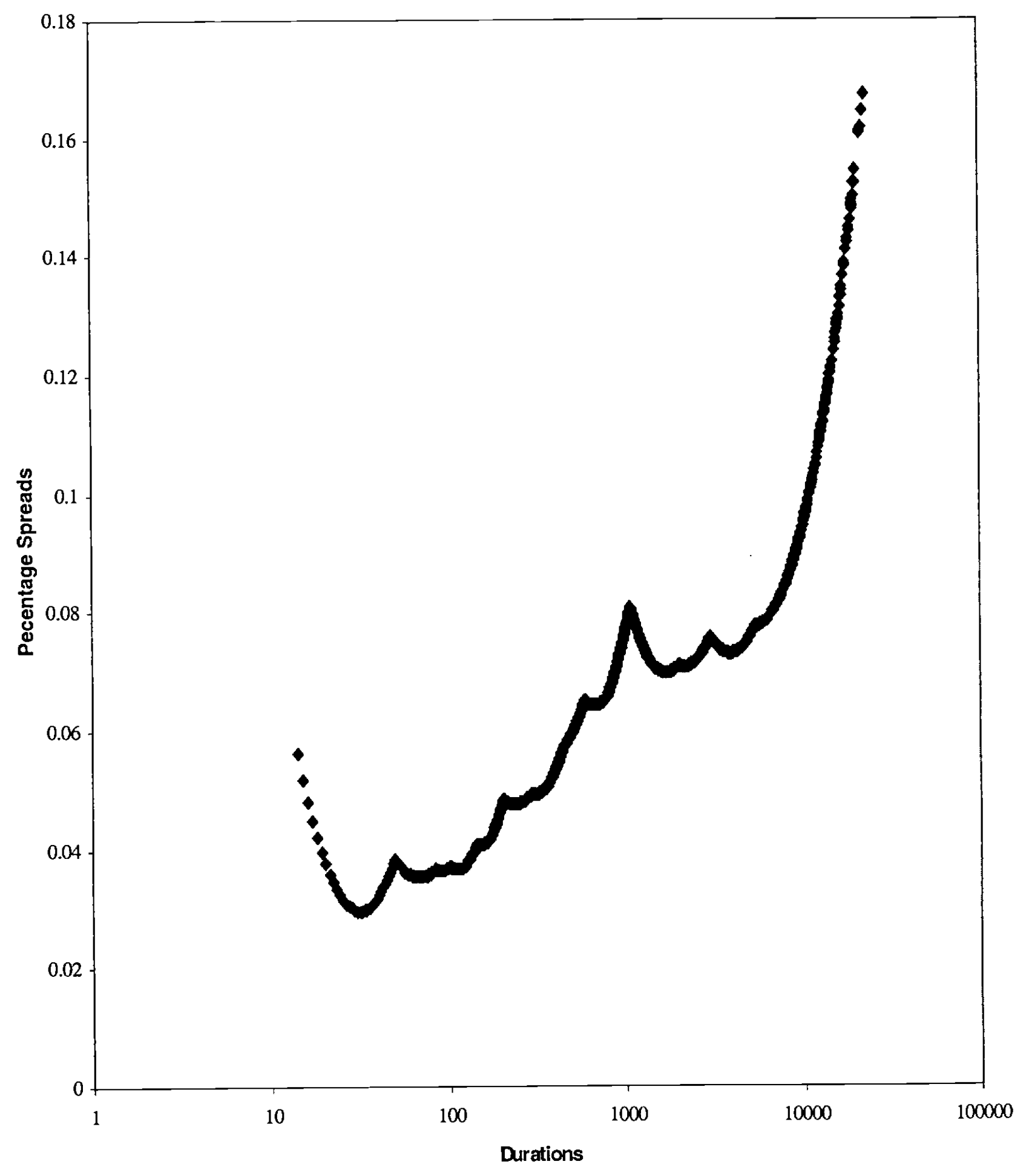




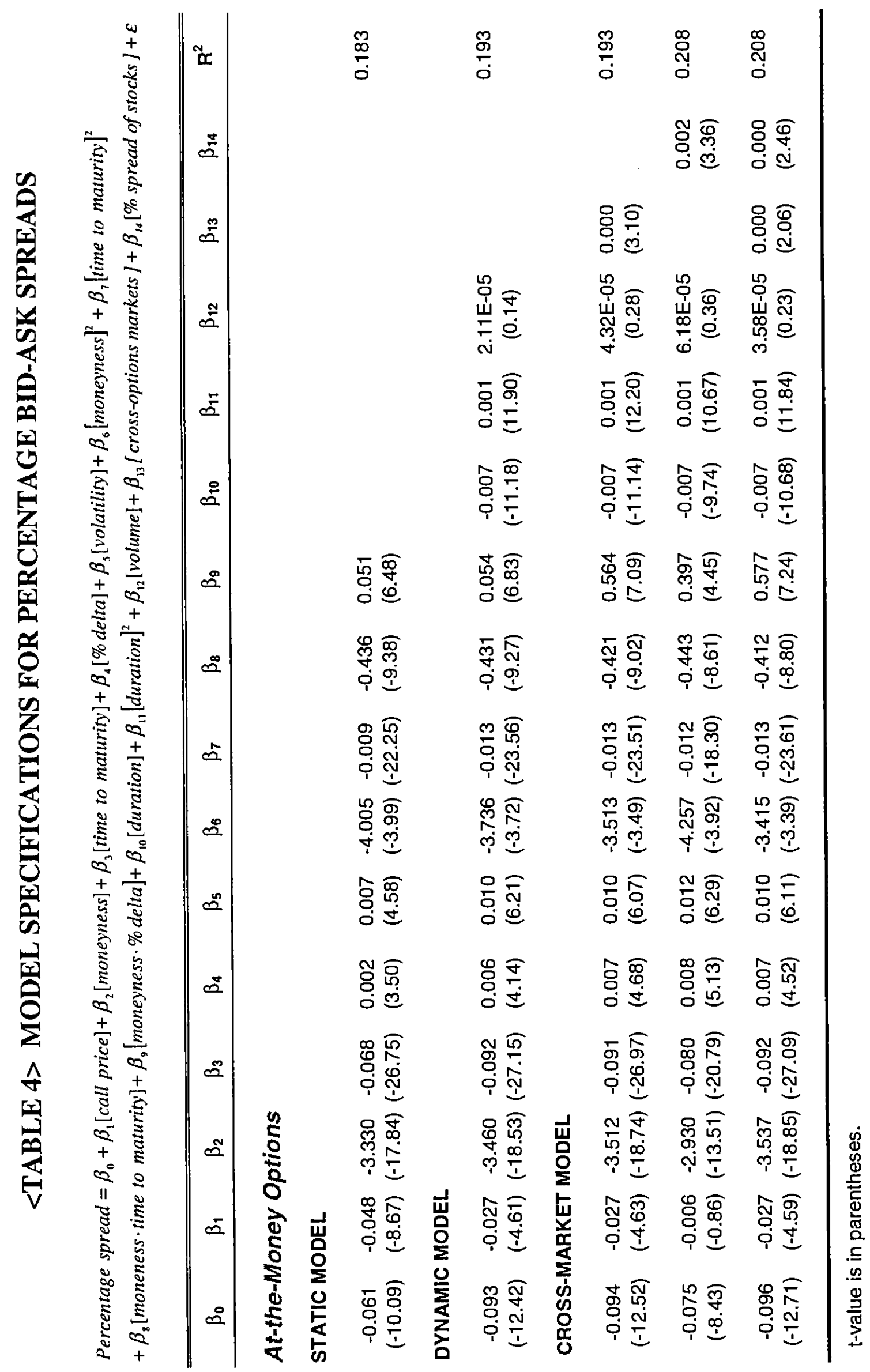




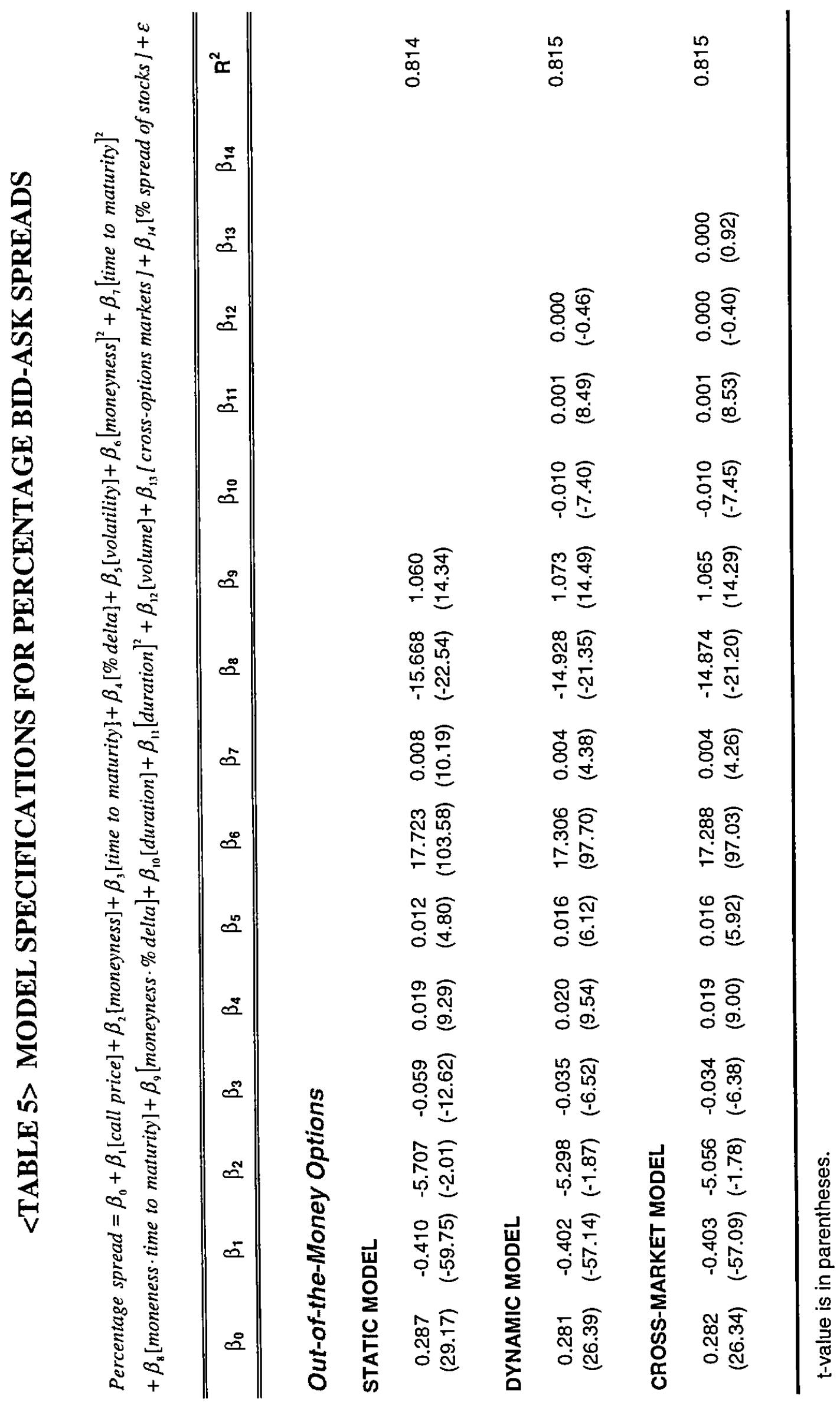




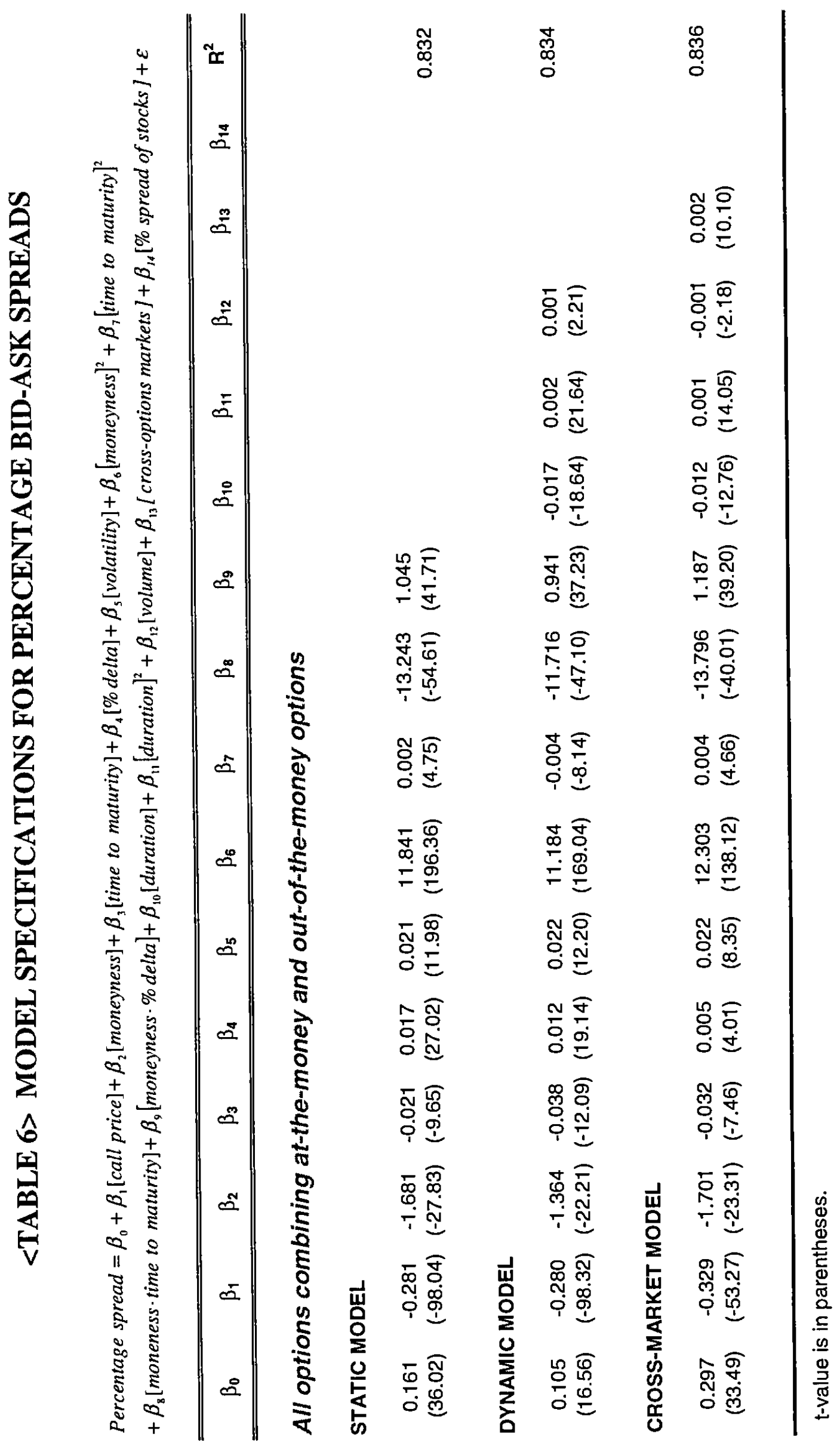

